\title{
Schiff Bases of Isatin and Adamantane-1-Carbohydrazide: Synthesis, Characterization and Anticonvulsant Activity
}

\author{
Hind M. Osman, ${ }^{1}$ Tilal Elsaman $\mathbb{D}^{2,1}$ Bashir A. Yousef ${ }^{\circ},{ }^{3}$ Esraa Elhadi, ${ }^{4}$ \\ Aimun A. E. Ahmed $\mathbb{D}^{\mathrm{D}}{ }^{5,6}$ Eyman Mohamed Eltayib $\mathbb{D}^{\mathrm{D}},{ }^{7,8}$ Malik Suliman Mohamed $\mathbb{D},{ }^{7,9}$ \\ and Magdi Awadalla Mohamed $\mathbb{D}^{2,10}$ \\ ${ }^{1}$ Department of Pharmaceutical Chemistry, College of Pharmacy, Omdurman Islamic University, Omdurman, Sudan \\ ${ }^{2}$ Department of Pharmaceutical Chemistry, College of Pharmacy, Jouf University, Sakaka, Saudi Arabia \\ ${ }^{3}$ Department of Pharmacology, Faculty of Pharmacy, University of Khartoum, Khartoum, Sudan \\ ${ }^{4}$ Department of Pharmacology, School of Pharmaceutical Sciences, China Pharmaceutical University, Nanjing, China \\ ${ }^{5}$ Department of Pharmacology, College of Pharmacy, Omdurman Islamic University, Omdurman, Sudan \\ ${ }^{6}$ Department of Pharmacology, Faculty of Medicine, Al Baha University, Al Bahah, Saudi Arabia \\ ${ }^{7}$ Department of Pharmaceutics, College of Pharmacy, Jouf University, Sakaka, Saudi Arabia \\ ${ }^{8}$ Department of Pharmaceutics, Faculty of Pharmacy, Al-Neelain University, Khartoum, Sudan \\ ${ }^{9}$ Department of Pharmaceutics, Faculty of Pharmacy, University of Khartoum, Khartoum, Sudan \\ ${ }^{10}$ Department of Pharmaceutical Chemistry, Faculty of Pharmacy, University of Khartoum, Khartoum, Sudan
}

Correspondence should be addressed to Tilal Elsaman; telbashir@ju.edu.sa

Received 9 October 2020; Accepted 4 January 2021; Published 25 January 2021

Academic Editor: Pedro M. Mancini

Copyright (c) 2021 Hind M. Osman et al. This is an open access article distributed under the Creative Commons Attribution License, which permits unrestricted use, distribution, and reproduction in any medium, provided the original work is properly cited.

\begin{abstract}
Epilepsy is the most common neurological condition and cause of substantial morbidity and mortality. In the present study, the molecular hybridization tool was adopted to obtain six Schiff bases of isatin and adamantane-1-carbohydrazide (18-23). Then, their anticonvulsant activity was evaluated using pentylenetetrazole- (PTZ-) induced seizure model using phenobarbitone as a positive control. Our findings showed that compounds 18-23 provided significant protection against PTZ-induced seizure, and maximum activities were associated with compound 23. Moreover, all investigated compounds increased the latency of induced convulsion and reduced the duration of epilepsy with compound 23 being the best. Interestingly, most of the synthesized molecules showed reduction in neurological symptoms and severity of the seizure. Molecular docking studies suggest GABA-A receptor as a potential target, and in silico ADME screening revealed that the pharmaceutical properties of compound 23 are within the specified limit. Thus, compound 23 was identified as a promising candidate that warrants further drug discovery processes.
\end{abstract}

\section{Introduction}

Epilepsy is one of the neurological disorders that involves abnormal electrical activity in the central nervous system, which results in spontaneous and recurrent seizures with or without loss of consciousness [1]. It is a group of diverse syndromes affecting more than 50 million people of different ages worldwide, and it poses a substantial economic burden in terms of health care services and lost productivity at work
[2]. Furthermore, the presence and magnitude of related psychiatric conditions, such as anxiety and depressive disorders, make seizures worse, and can impair the quality of life in several domains [2]. Currently used antiepileptic drugs, such as phenytoin, phenobarbitone, and carbamazepine, are associated with serious side effects, and in several cases, they failed to manage seizures adequately. Moreover, studies have disclosed that around $30 \%$ of patients are resistant to the conventional antiepileptic therapy [3-5]. In 
this context, there is an urgent need to develop more efficacious antiepileptic drugs with reduced potential to induce side effects. Such new antiepileptic drugs should be explored based on original ideas to open new avenues for adequate control of this devastating disease [6-8]. Researchers now follow three main modalities in attempts to develop new antiepileptic drugs: (I) chemical optimization of currently existing drugs, (II) discovery of new therapeutic entities against novel potential therapeutic targets, and (III) conventional drug screening (nontarget-driven) approach [8].

Isatin (indoline-2,3-dione) (1) (Figure 1) is a heterocyclic structure with a wide range of biodynamic activities [9-12].

Several isatin-based derivatives (Figure 1) have been reported to possess anticonvulsant properties [13]. Some of these were reported for their enhanced antiepileptic activity through a significant elevation of GABA levels in the brain [14].

Adamantane (5) (Figure 2) and its derivatives were revealed in the literature to possess broad-spectrum pharmacological activities [15]. By virtue of its hydrophobic nature, adamantane was extensively adopted in drug discovery as a modifier of the pharmaceutical and pharmacokinetic properties of several drug classes [16-18]. To this end, incorporation of adamantane moiety has been shown to enhance CNS penetration of the modified structures, and consequently, this has been considered of value in promoting CNS drug targeting [15]. In this regard, adamantane derivatives (6-8) (Figure 2) have been documented to display excellent anticonvulsant activity via different modes of action including the blockade of the NMDA-activated channel [19-23].

Despite the long clinical success of conventional antiepileptic drugs, it has been established that the concept of "one-drug-one-target-one-disease" is unsatisfactory in treating this heterogeneous disease. Furthermore, newgeneration antiepileptic drugs have shown low efficacy in adequate controlling of seizures [24]. Thus, there is an urgent need to deliver new potent antiepileptic drugs.

Recently, literature has grown up around the theme of molecular hybridization as an efficient drug design strategy that affords ligands to be able to interact with multiple targets of interest [25]. This strategy involves the fusion of two pharmacophoric moieties in a single structural framework [26].

Considering all these factors into account, the study presented here aims to contribute to the growing area of antiepileptic drug discovery by exploring new molecular architecture (Figure 3) designed through hybridization of two pharmacophoric moieties, namely, isatin and adamantane. The resultant hybrid molecules are expected to possess an enhanced CNS penetration, together with their ability to modulate multiple targets involved in the etiology of epilepsy. Different substitution patterns with different electronic and/or hydrophobic environments were adopted to get an insight into their possible SAR.

\section{Results and Discussion}

2.1. Chemistry. Initially, adamantane-1-carboxylic acid (9) was subjected to esterification (Scheme 1) to afford methyl adamantane-1-carboxylate (10) in good yield
(85\%). Subsequent reaction of 10 with hydrazine hydrate under reflux condition (Scheme 1) provided adamantane-1-carbohydrazide (11) in excellent yield (98\%) $[27,28]$.

The 5-substituted isatin derivatives 12-14 are commercially available, while the key intermediates 15 and 16 were yielded by treatment of 12 and 13 with $37 \%$ formalin under reflux conditions and were obtained in 50\% yield [29]. On the contrary, intermediate 17 (62\%) was derivatized through alkylation of 5-bromoisatin (13) with benzyl chloride in DMF at $80^{\circ} \mathrm{C}$ using catalytic amount of potassium carbonate [29]. Finally, the designed Schiff bases (18-23) (47-82\%) were prepared following the synthetic route depicted in Scheme 2 via condensation of adamantane-1-carbohydrazide (11) with the appropriate isatin derivative (12-17) according to a reported procedure [11].

All the synthesized compounds were purified by recrystallization from the appropriate solvent, and their chemical structures were verified by recording their IR, ${ }^{1} \mathrm{H}$, and ${ }^{13} \mathrm{C}$ NMR.

Ester (10) and hydrazide (11) showed strong absorptions at 1730 and $1613 \mathrm{~cm}^{-1}$, respectively, indicating the presence of carbonyl functionality in each case. Furthermore, two distinct absorption bands become visible at 3328 and $3280 \mathrm{~cm}^{-1}$ indicating $\mathrm{NH}_{2}$ stretching in 11. 1-Hdroxymethylisatins 15 and 16 showed broad bands ranging from 3313 to $3446 \mathrm{~cm}^{-1}$ corresponding to the free $\mathrm{OH}$ group. N-Alkyl isatin 17 displayed absorption bands at $3091 \mathrm{~cm}^{-1}$ and $2972 \mathrm{~cm}^{-1}$ corresponding to aromatic $\mathrm{C}-\mathrm{H}$ stretching and aliphatic $\mathrm{C}-\mathrm{H}$ stretching, respectively. The IR spectra of Schiff bases 18-23 were apparently distinct from their respective intermediates. To this end, the appearance of a sharp band in the range of $1670-1690 \mathrm{~cm}^{-1}$ denotes stretching of hydrazide carbonyl (CONHN) in all Schiff bases. In addition, bands around $1700 \mathrm{~cm}^{-1}$ correspond to amide carbonyl (CONH) functionality in compounds $18-20$.

The ${ }^{1} \mathrm{H}$ NMR spectra of the synthesized compounds are in consistence with the proposed chemical structures. For Schiff bases 18-23, the spectra displayed the adamantane1 -carbohydrazide and the indole sets of protons in a manner consistent with their designed structures. The 15 aliphatic protons in the adamantane moiety are exhibited as multiplets in a range of $\delta 1.59-2.13 \mathrm{ppm}[30] .{ }^{1} \mathrm{H}$ NMR spectra of 18 and 21 displayed the four aromatic protons of the indole ring ranging from $\delta 6.45$ to $8.22 \mathrm{ppm}$, which are consistent with the reported data [31, 32]. In 5-substituted isatin derivatives, $19,20,22$, and 23 , the three aromatic hydrogens are relatively shifted downfield due to 5-substitution by the electron-withdrawing group. Compounds 18-20 showed a broad singlet peak at $\delta 9.02-11.44 \mathrm{ppm}$ integrated to one proton assigned for the deshielded ArNHCO proton of the indole ring. However, this peak is not displayed for $\mathrm{N}$-alkylated compounds (21-23). 1Hydroxy methylated products 21 and 22 displayed a broad singlet peak at $\delta 8.70-8.89 \mathrm{ppm}$ integrated to one proton assigned to hydroxyl group hydrogen. Moreover, a singlet signal at $\delta 3.58-3.94 \mathrm{ppm}$ integrated for $2 \mathrm{H}$ is ascribed to $\mathrm{ArNCH}_{2} .{ }^{1} \mathrm{H}$ NMR spectrum of N-benzyl derivative 23 exhibited five aromatic hydrogens attributed to the benzyl 


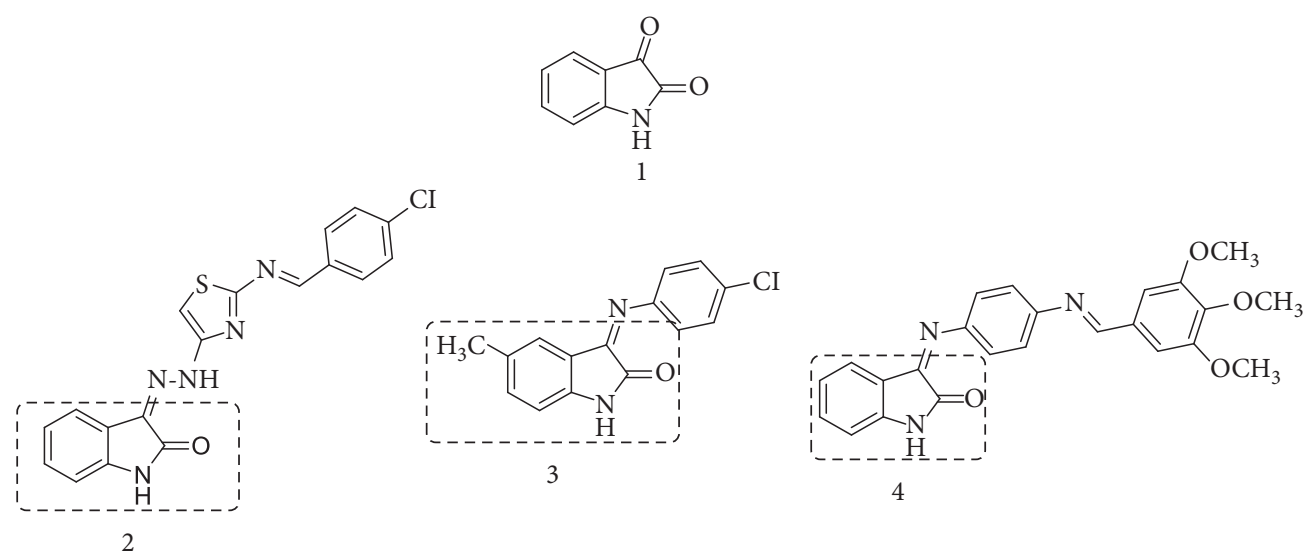

FIGURE 1: Chemical structures of the promising anticonvulsant isatin derivative.

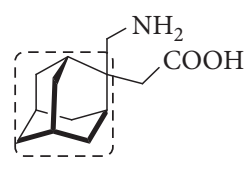

6

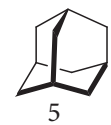

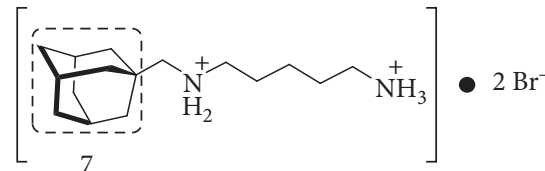

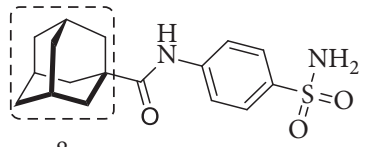

8

FIGURE 2: Chemical structure of adamantane derivatives reported with promising anticonvulsant activity.

group protons at $\delta 7-7.5 \mathrm{ppm}$ beside the aromatic protons of the indole ring.

As a general pattern, the ${ }^{13} \mathrm{C}$ NMR spectra in all compounds are in consistence with the chemical structures and with the previously reported data [32-34]. The most observable trend in ${ }^{13} \mathrm{C}$ NMR spectra is related to the number of peaks displayed at the aromatic region that are always equal to the sum of the equivalent aromatic carbons for each compound. The ${ }^{13} \mathrm{C}$ NMR spectra exhibit characteristic signals resonating around $\delta$ 160.28-161.69 ppm corresponding to hydrazide amide (NHCO) carbon. Additional signals centered at $\delta$ 175.21-176.76 ppmare attributed to lactam carbonyl (ArNCO) carbon. Compounds 21 and 22 exploited signals resonating at $\delta 73.34 \mathrm{ppm}$ attributed to $(\mathrm{N}-$ $\mathrm{CH}_{2}-\mathrm{OH}$ ) methylene carbon, while benzylic methylene of 23 is shown at $\delta 43 \mathrm{ppm}$.

\subsection{Anticonvulsant Activity}

2.2.1. Protection Rate \% of the Synthesized Compounds against PTZ-Induced Seizure. Protection rate \% from PTZinduced seizure was measured for the six synthesized compounds (18-23) along with the positive control, phenobarbital, at two dose levels (30 and $100 \mathrm{mg} / \mathrm{kg}$ ). On the contrary, the negative control group received only $5 \%$ methylcellulose. Contrary to what has been reported [35], phenobarbital at the two tested doses, 30 and $100 \mathrm{mg} / \mathrm{kg}$, showed $25 \%$ and $100 \%$ protection against PTZ-induced seizure, respectively (Figure 4). Compound 18 at $100 \mathrm{mg} / \mathrm{kg}$ displayed a protection rate of $58 \%$ (Figure 4 ), while at the lower dose, it was inactive. Insertion of the bromo group at $\mathrm{C} 5$ of the indole ring rendered compound 19 inactive at the two tested doses (Figure 4). On the contrary, chloro substitution at the same position as in compound 20 led to significant protection (40\%) at the low dose, while no activity was observed for this compound at the higher dose (Figure 4). Hydroxymethylation of position 1 for Schiff bases 18 and 19 afforded compounds 21 and 22, respectively. These compounds demonstrated significant seizure protection rates at the low dose $(>40 \%)$, while their bioactivity reduced at the higher doses. These results propose that manipulation of position 1 by polar functionality improves the anticonvulsant activity. Based on this, we tried to introduce the nonpolar motif through N-benzylation of the most potent compound 22 to furnish the more lipophilic compound 23. Being superior to the standard drug phenobarbitone in terms of seizure protection rate, compound 23 emerged as the most potent as it displayed $67 \%$ seizure protection at the low dose of $30 \mathrm{mg} / \mathrm{kg}$ and $58 \%$ at the higher dose of $100 \mathrm{mg} / \mathrm{kg}$ as shown in Figure 4.

Correlation between lipophilicity and anticonvulsant activity was reported [36-38]. For anticonvulsant agents to be effective, they have to attain adequate concentration in the brain through the efficient crossing of BBB. All compounds investigated here were found to have CLogP values (Table 1) above 2, which is an important feature for effective CNS penetrability [38]. It is worthnoting that the most 


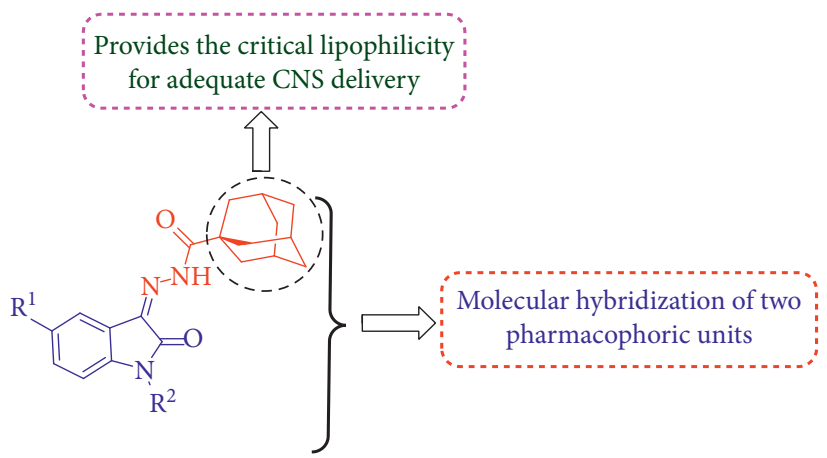

Figure 3: General chemical structure of the hybrid molecules.

efficacious compound 23 has a CLogP value of 6.952, which exceeds that of the other compounds. In this regard, the high potency for compound 23 could be partially explained based on its higher lipophilicity, which directly influences the CNS delivery.

2.2.2. Effect of Synthesized Compounds on Latency and Duration of PTZ-Induced Seizure. The time in seconds of the onset of the seizure, expressed as the latency of convulsion, and the duration of the PTZ-induced seizure were obtained for the six synthesized compounds and phenobarbital at 30 and $100 \mathrm{mg} / \mathrm{kg}$ doses. As illustrated in Table 2, compounds 18-23 increased the latency of convulsion with compound 23 exhibiting a significant delay on the onset of PTZ-induced seizures $(1263 \pm 501.2 \mathrm{sec})$ compared to the positive control $(467.5 \pm 56.41 \mathrm{sec})$ at $30 \mathrm{mg} / \mathrm{kg}$ dose. These results are consistent with those disclosed in the literature which described the influence of isatin-inspired compounds on latency time of convulsions [14]. Furthermore, except compound 20 at the low dose, all the synthesized Schiff bases were found effective in shortening the epileptic duration (Table 2) with significant effect observed for compounds 18 and 21-23. Compounds 18, 22 , and 23 at low doses $(30 \mathrm{mg} / \mathrm{kg}$ ) were more effective than the standard drug at the same dose, pointing to their seizure protection ability at relatively lower doses. It is worthwhile to mention that these compounds displayed better protection at lower doses $(30 \mathrm{mg} / \mathrm{kg})$ rather than the higher doses $(100 \mathrm{mg} /$ $\mathrm{kg}$ ) as shown in Table 2.

2.2.3. Effect of the Investigated Compounds on Neurological Signs of PTZ-Induced Seizure. The neurological signs and severity of the PTZ-induced seizure were observed for 1 hour after the administration of compounds 18-23 along with phenobarbitone. As shown in Table 3, all candidate compounds demonstrated a reduction in PTZ-induced neurological signs of seizures. The most potent compound 23 was proved to be better than the standard drug in minimizing these signs at the dose $(30 \mathrm{mg} / \mathrm{kg})$.

2.2.4. Neurotoxicity of the Investigated Compounds. Neurotoxicity of compounds 18-23, along with the standard drug, was assessed for 1 hour after the induction of the seizure. To this end, compounds 18-23, together with phenobarbitone, exhibited CNS depressive effects such as somnolence and sleep after 1 hour of seizure induction, as depicted in Table 4. While compounds 19 and 21 revealed signs of CNS toxicity such as lack of exploratory behavior and catalepsy, the most potent candidate 23 at $30 \mathrm{mg} / \mathrm{kg}$ displayed a similar pattern of neurological toxicity to the standard drug at the same tested dose.

\subsection{Molecular Modelling Studies}

2.3.1. Docking on $G A B A_{A}$ Receptor (3IP9). GABA is the majorCNS inhibitory neurotransmitter involved in the pathophysiology of epilepsy [39]. Therapeutic agents acting through the modulation of the $\mathrm{GABA}_{\mathrm{A}}$ receptor have been reported to inhibit seizures in both experimental animals and humans [40]. It has been reported that PTZ mediates its convulsive action through direct inhibition of the GABAergic process in the CNS [41]. Since the synthesized compounds antagonized the convulsion induced by PTZ, it probably may exert its anticonvulsant activities through activation of GABAergic transmission in similar mechanisms of barbiturates such as phenobarbital [42]. Molecular docking is a powerful tool for investigating the potential action mode of biodynamically active molecules. Therefore molecular docking analysis has been carried out to assess the potential molecular interaction patterns of compounds $18-23$ with the $\mathrm{GABA}_{\mathrm{A}}$ receptor. The docking energies $(\mathrm{kcal} / \mathrm{mol})$ of the synthesized compounds against phenobarbitone are summarized in Table 1. As shown in Table 1, compounds 18-23 exhibited lower docking energies ranging from -7.6 to $-8.6 \mathrm{kcal} / \mathrm{mol}$, which are relatively far less than the standard drug phenobarbitone $(-5.903 \mathrm{kcal} / \mathrm{mol})$. This could be partially explained by the formation of more stable complexes as a consequence of better positioning of these compounds in the active center of the receptor. While the relatively less active compound 22 displayed the lowest binding energy $(-8.662 \mathrm{kcal} /$ $\mathrm{mol}$ ), the most potent compound 23 showed a binding energy of $-7.875 \mathrm{kcal} / \mathrm{mol}$. This could be rationalized by the relatively high hydrophobicity of compound $23(\mathrm{C} \log \mathrm{P}=6.952)$, which facilitates the penetration of 23 into the brain in high concentration levels. The $3 \mathrm{D}$ interaction of the $\mathrm{GABA}_{\mathrm{A}}$ receptor with phenobarbital and compound 23 is shown in Figure 5, indicating hydrophobic interaction of the isatin moiety, which is further augmented by deep longitudinal insertion of the benzyl 


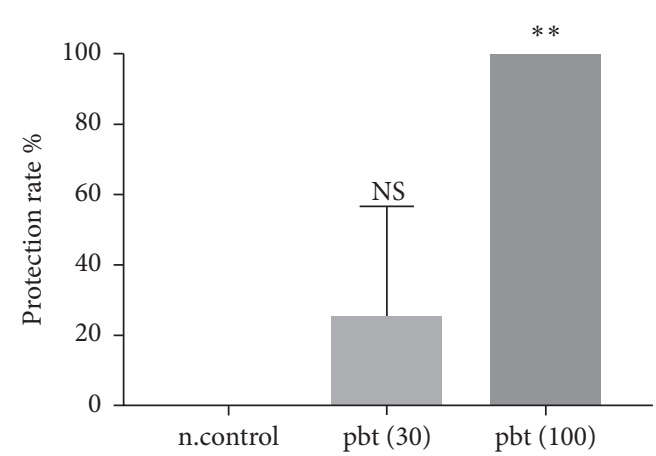

(a)

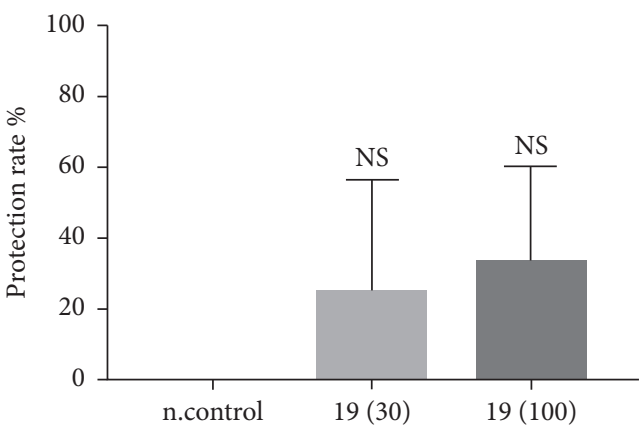

(c)

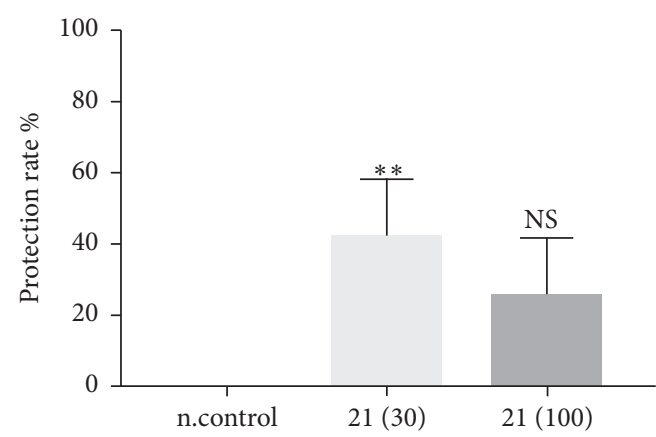

(e)

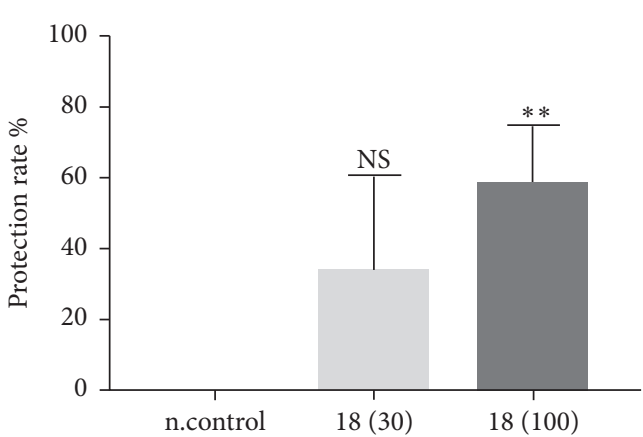

(b)

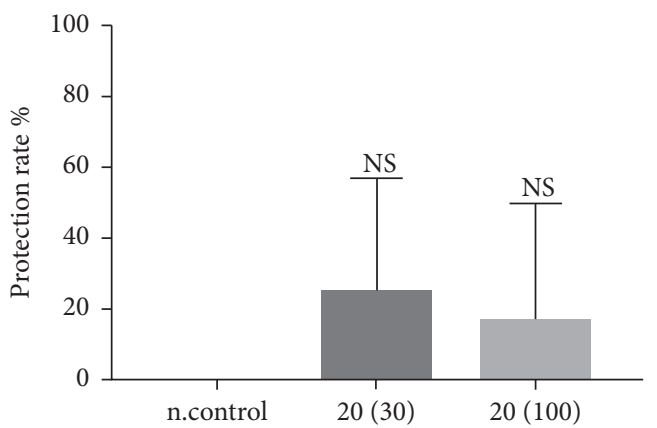

(d)

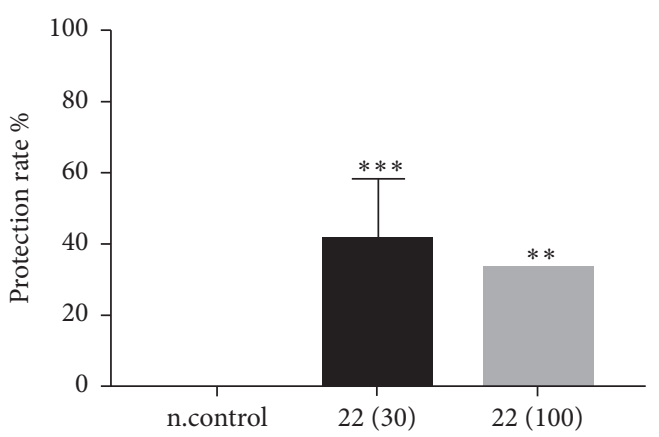

(f)

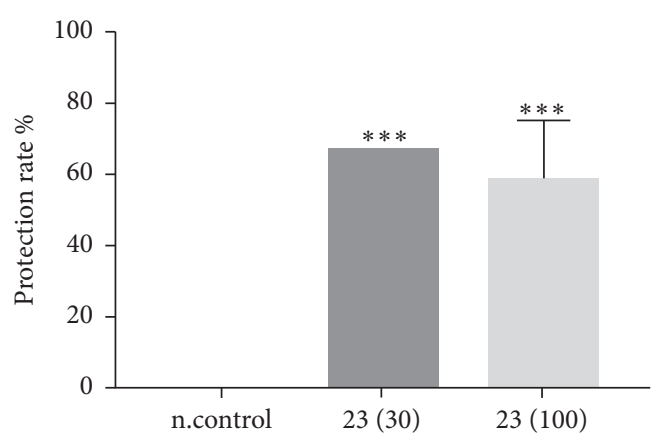

(g)

FIgURE 4: Protection rate of the synthesized Schiff bases (18-23) along with the standard drug phenobarbitone against PTZ-induced seizure.

group in the hydrophobic pocket. Such an interaction has been documented in the literature for potent anticonvulsant compounds proposing the necessity of aryl/alkyl hydrophobic group as key structural elements [43]. Thus, the superior activity of 23 appears to be due to the unique existence of the benzyl group which aid to (i) Hydrophobic interaction with the binding site; (ii) Increase CNS penetrability.
2.3.2. Drug-Likeness Study. Prediction of ADMET properties of the titled compounds such as partition coefficient (CLogP), topological polar surface area (TPSA), and number of rotatable bonds (Nrotb), in addition to violations of Lipinski's and Veber's parameters, was performed using SwissADME server. As shown in Table 1, all compounds were in complete agreement with Lipinski's rule of five and 


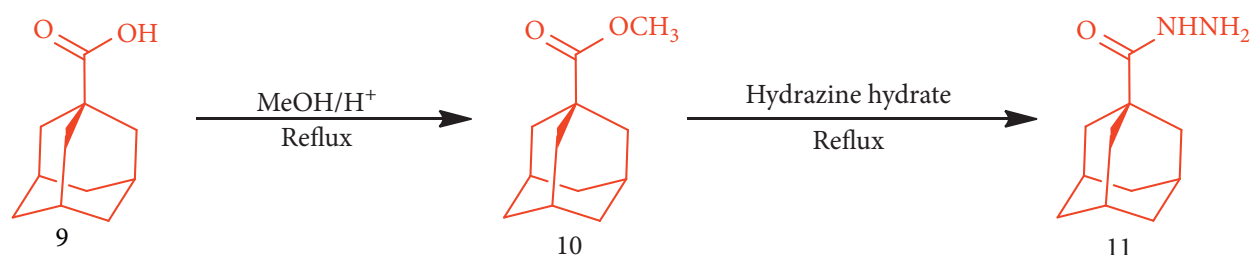

Scheme 1: Synthesis of adamantane-1-carbohydrazide.

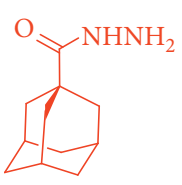

11

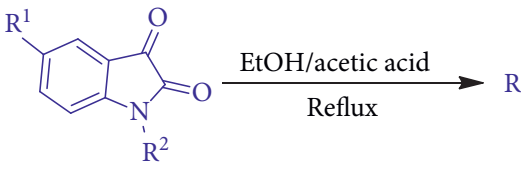

$12-17$<smiles>[R]c1ccc2c(c1)/C(=N/NC(=O)C13CC4CC(CC(C)(C4)C1)C3)NC2=O</smiles>

$18-23$

$$
\begin{array}{ll}
\text { 12: } \mathrm{R}^{1}=\mathrm{H} ; \mathrm{R}^{2}=\mathrm{H} & 18: \mathrm{R}^{1}=\mathrm{H} ; \mathrm{R}^{2}=\mathrm{H} \\
13: \mathrm{R}^{1}=\mathrm{Br} ; \mathrm{R}^{2}=\mathrm{H} & 19: \mathrm{R}^{1}=\mathrm{Br} ; \mathrm{R}^{2}=\mathrm{H} \\
14: \mathrm{R}^{1}=\mathrm{CI} ; \mathrm{R}^{2}=\mathrm{H} & 20: \mathrm{R}^{1}=\mathrm{CI} ; \mathrm{R}^{2}=\mathrm{H} \\
15: \mathrm{R}^{1}=\mathrm{H} ; \mathrm{R}^{2}=\mathrm{CH}_{2} \mathrm{OH} & 21: \mathrm{R}^{1}=\mathrm{H} ; \mathrm{R}^{2}=\mathrm{CH}_{2} \mathrm{OH} \\
16: \mathrm{R}^{1}=\mathrm{Br} ; \mathrm{R}^{2}=\mathrm{CH}_{2} \mathrm{OH} & 22: \mathrm{R}^{1}=\mathrm{Br} ; \mathrm{R}^{2}=\mathrm{CH}_{2} \mathrm{OH} \\
17: \mathrm{R}^{1}=\mathrm{Br} ; \mathrm{R}^{2}=\mathrm{CH}_{2} \mathrm{Ph} & 23: \mathrm{R}^{1}=\mathrm{Br} ; \mathrm{R}^{2}=\mathrm{CH}_{2} \mathrm{Ph}
\end{array}
$$

Scheme 2: Synthesis of target hybrid molecules 18-23.

TABLE 1: Drug-like properties and docking energies of compounds 18-23.

\begin{tabular}{lccccccc}
\hline Compound & CLogP & MW $^{\mathrm{a}}$ & TPSA $^{\mathrm{b}}$ & HBA $^{\mathrm{c}}$ & HBD $^{\mathrm{d}}$ & Nrotb $^{\mathrm{e}}$ & Docking energies $\left(\mathrm{kcal} / \mathrm{mol}^{\text {) }}\right.$ \\
\hline Phenobarbitone & 1.41 & 232.24 & 75.27 & 2 & 3 & 2 & -5.903 \\
18 & 3.445 & 323.39 & 70.56 & 3 & 2 & 3 & -7.629 \\
19 & 4.308 & 402 & 70.57 & 3 & 2 & 3 & -7.991 \\
20 & 4.158 & 357.8 & 70.56 & 3 & 2 & 3 & -7.902 \\
21 & 3.958 & 353 & 82 & 4 & 2 & 4 & -8.357 \\
22 & 4.461 & 432 & 82 & 4 & 2 & 4 & -8.662 \\
23 & 6.952 & 492.4 & 61.77 & 3 & 1 & 5 & -7.875 \\
\hline
\end{tabular}

${ }^{\mathrm{a}}$ Molecular weight; ${ }^{\mathrm{b}}$ topological polar surface area; ${ }^{\mathrm{c}}$ hydrogen bond acceptor; ${ }^{\mathrm{d}}$ hydrogen bond donor; ${ }^{\mathrm{e}}$ number of rotatable bonds.

TABLE 2: Effect of the synthesized compounds on latency and duration of PTZ-induced seizure.

\begin{tabular}{lccc}
\hline Compound & Dose $(\mathrm{mg} / \mathrm{kg})$ & Time $(\mathrm{sec}$.$) of the latency of convulsions (MEN \pm$ SEM) & Duration (sec.) of convulsion $(\mathrm{MEN} \pm \mathrm{SEM})$ \\
\hline Methylcellulose & $0.004 \mathrm{~mL} / \mathrm{g}$ & $280.5 \pm 54.06$ & $116 \pm 12.99$ \\
\multirow{2}{*}{ Phenobarbitone } & 30 & $467.5 \pm 56.41$ & $58 \pm 10.68^{*}$ \\
& 100 & Nil & $34.25 \pm 4.80^{* * *}$ \\
\hline \multirow{2}{*}{18} & 30 & $313.3 \pm 84.47$ & $62.50 \pm 9.77^{*}$ \\
\hline \multirow{2}{*}{19} & 100 & $780 \pm 243.7$ & $95.00 \pm 27.54$ \\
& 30 & $539.3 \pm 169.8$ & $82.75 \pm 13.07$ \\
\hline \multirow{2}{*}{20} & 100 & $494.8 \pm 8.179$ & $115.0 \pm 5.00$ \\
& 30 & $600.0 \pm 73.48$ & $77.5 \pm 10.31$ \\
\multirow{2}{*}{21} & 100 & $675.0 \pm 137.2$ & $64.50 \pm 8.95^{*}$ \\
& 30 & $429.0 \pm 94.19$ & $55.00 \pm 5.00^{* *}$ \\
\hline \multirow{2}{*}{22} & 100 & $432.5 \pm 124.7$ & $46.00 \pm 8.495^{* *}$ \\
\hline \multirow{2}{*}{23} & 30 & $513.5 \pm 70.89$ & $45.00 \pm 0.00^{* *}$ \\
\hline
\end{tabular}

Data analyzed by one-way ANOVA followed by Dunnett's test $(n=4) ;{ }^{*} P<0.05,{ }^{* *} P<0.01$, and ${ }^{* * *} P<0.001$ when compared with the control group. 
TABLE 3: Effect of synthesized compounds on neurological signs* of PTZ-induced seizure 1 hour after induction.

\begin{tabular}{|c|c|c|c|c|c|c|c|c|}
\hline Compound & Dose (mg\kg) & Myoclonic jerks & $\begin{array}{l}\text { S-shape in } \\
\text { the tail }\end{array}$ & $\begin{array}{l}\text { Upright } \\
\text { position }\end{array}$ & Head nodding & $\begin{array}{c}\text { Loss of postural } \\
\text { control }\end{array}$ & $\begin{array}{l}\text { Muscle } \\
\text { flaccid }\end{array}$ & $\begin{array}{l}\text { A tonic or } \\
\text { clonic }\end{array}$ \\
\hline Methyl cellulose 5\% & $0.004 \mathrm{~mL} / \mathrm{g}$ & +++ & +++ & ++ & +++ & +++ & +++ & +++ \\
\hline Phenobarbital & $\begin{array}{c}30 \\
100 \\
\end{array}$ & $\begin{array}{c}++ \\
\text { Nil }\end{array}$ & $\begin{array}{l}++ \\
\text { Nil }\end{array}$ & $\begin{array}{c}+ \\
\text { Nil }\end{array}$ & $\begin{array}{c}+ \\
\text { Nil }\end{array}$ & $\begin{array}{l}++ \\
\text { Nil }\end{array}$ & $\begin{array}{l}++ \\
\text { Nil }\end{array}$ & $\begin{array}{c}+ \\
\text { Nil }\end{array}$ \\
\hline 18 & $\begin{array}{c}30 \\
100 \\
\end{array}$ & $\begin{array}{l}++ \\
\text { Nil } \\
\end{array}$ & $\begin{array}{c}++ \\
+ \\
\end{array}$ & $\begin{array}{c}\text { Nil } \\
+ \\
\end{array}$ & $\begin{array}{l}\text { Nil } \\
\text { Nil } \\
\end{array}$ & $\begin{array}{c}++ \\
+ \\
\end{array}$ & $\begin{array}{l}+ \\
+ \\
\end{array}$ & $\begin{array}{c}++ \\
+++ \\
\end{array}$ \\
\hline 19 & $\begin{array}{c}30 \\
100 \\
\end{array}$ & $\begin{array}{l}++ \\
++\end{array}$ & $\begin{array}{l}++ \\
++ \\
\end{array}$ & $\begin{array}{c}+ \\
++ \\
\end{array}$ & $\begin{array}{c}++ \\
+ \\
\end{array}$ & $\begin{array}{l}++ \\
++ \\
\end{array}$ & $\begin{array}{c}++ \\
+ \\
\end{array}$ & $\begin{array}{c}++++ \\
+++\end{array}$ \\
\hline 20 & $\begin{array}{c}30 \\
100 \\
\end{array}$ & $\begin{array}{l}+++ \\
+++\end{array}$ & $\begin{array}{c}+ \\
++ \\
\end{array}$ & $\begin{array}{c}\text { Nil } \\
+ \\
\end{array}$ & $\begin{array}{l}+++ \\
+++\end{array}$ & $\begin{array}{l}++ \\
++ \\
\end{array}$ & $\begin{array}{l}++ \\
++ \\
\end{array}$ & $\begin{array}{l}++ \\
++ \\
\end{array}$ \\
\hline 21 & $\begin{array}{c}30 \\
100 \\
\end{array}$ & $\begin{array}{l}++ \\
++ \\
\end{array}$ & $\begin{array}{l}++ \\
++ \\
\end{array}$ & $\begin{array}{l}+ \\
+ \\
\end{array}$ & $\begin{array}{l}\text { Nil } \\
\text { Nil } \\
\end{array}$ & $\begin{array}{c}+ \\
++ \\
\end{array}$ & $\begin{array}{l}+ \\
+ \\
\end{array}$ & $\begin{array}{l}++ \\
++ \\
\end{array}$ \\
\hline 22 & $\begin{array}{c}30 \\
100 \\
\end{array}$ & $\begin{array}{c}++ \\
++ \\
\end{array}$ & $\begin{array}{l}++ \\
++ \\
\end{array}$ & $\begin{array}{c}+ \\
++ \\
\end{array}$ & $\begin{array}{l}++ \\
+ \\
\end{array}$ & $\begin{array}{l}++ \\
++ \\
\end{array}$ & $\begin{array}{c}++ \\
+++\end{array}$ & $\begin{array}{c}+ \\
++ \\
\end{array}$ \\
\hline 23 & $\begin{array}{c}30 \\
100 \\
\end{array}$ & $\begin{array}{l}++ \\
++ \\
\end{array}$ & $\begin{array}{c}\text { Nil } \\
+ \\
\end{array}$ & $\begin{array}{c}\text { Nil } \\
+ \\
\end{array}$ & $\begin{array}{l}+ \\
+ \\
\end{array}$ & $\begin{array}{l}+ \\
+ \\
\end{array}$ & $\begin{array}{c}+ \\
\text { Nil } \\
\end{array}$ & $\begin{array}{c}+ \\
\text { Nil } \\
\end{array}$ \\
\hline
\end{tabular}

${ }^{*}$ The severity of the neurological signs: ${ }^{+}$mild, ${ }^{++}$moderate, and ${ }^{++}$severe.

TABLE 4: Neurotoxicity* of synthesized compounds during 1 hour of induction.

\begin{tabular}{|c|c|c|c|c|c|c|c|c|}
\hline Compound & $\begin{array}{c}\text { Dose } \\
(\mathrm{mg} \backslash \mathrm{kg})\end{array}$ & $\begin{array}{l}\text { Circular or } \\
\text { zigzag gait }\end{array}$ & $\begin{array}{c}\text { Abnormal } \\
\text { spread of legs }\end{array}$ & $\begin{array}{l}\text { Abnormal } \\
\text { posture }\end{array}$ & Tremor & $\begin{array}{l}\text { Lack of } \\
\text { exploratory } \\
\text { behavior }\end{array}$ & $\begin{array}{l}\text { Somnolence } \\
\text { or sleep }\end{array}$ & $\begin{array}{l}\text { Stupor or } \\
\text { catalepsy }\end{array}$ \\
\hline Methyl cellulose & - & + & ++ & ++ & ++ & Nil & Nil & Nil \\
\hline \multirow{2}{*}{ Phenobarbital } & 30 & + & ++ & + & + & Nil & $1 \mathrm{~h}$ & Nil \\
\hline & 100 & Nil & Nil & Nil & Nil & Nil & $1 \mathrm{~h}$ & Nil \\
\hline \multirow{2}{*}{18} & 30 & Nil & ++ & + & ++ & + & $1 \mathrm{~h}$ & Nil \\
\hline & 100 & Nil & + & + & ++ & + & $1 \mathrm{~h}$ & Nil \\
\hline \multirow{2}{*}{19} & 30 & + & ++ & ++ & ++ & ++ & $1 \mathrm{~h}$ & ++ \\
\hline & 100 & Nil & ++ & ++ & ++ & + & $1 \mathrm{~h}$ & ++ \\
\hline \multirow{2}{*}{20} & 30 & Nil & + & + & + & ++ & $1 \mathrm{~h}$ & Nil \\
\hline & 100 & ++ & ++ & + & + & $1 \mathrm{~h}$ & $1 \mathrm{~h}$ & $1 \mathrm{~h}$ \\
\hline \multirow{2}{*}{21} & 30 & Nil & + & + & + & + & $1 \mathrm{~h}$ & + \\
\hline & 100 & + & + & + & + & + & $1 \mathrm{~h}$ & Nil \\
\hline \multirow{2}{*}{22} & 30 & Nil & ++ & ++ & ++ & Nil & $1 \mathrm{~h}$ & Nil \\
\hline & 100 & Nil & ++ & ++ & ++ & Nil & $1 \mathrm{~h}$ & Nil \\
\hline \multirow{2}{*}{23} & 30 & Nil & + & + & ++ & Nil & $1 \mathrm{~h}$ & $1 \mathrm{~h}$ \\
\hline & 100 & Nil & Nil & + & + & + & $1 \mathrm{~h}$ & $1 \mathrm{~h}$ \\
\hline
\end{tabular}

${ }^{*}$ The severity of the neurotoxicity signs: ${ }^{+}$mild, ${ }^{++}$moderate, and ${ }^{+++}$severe.

Veber's parameters. Thus, these compounds have positive drug-likeness such as good oral bioavailability and favorable CNS penetrability and hence could be envisioned as promising and potential leads for further investigations.

\section{Experimental}

3.1. General. The starting adamantane-1-carboxylic acid, isatins, and alkyl halides were commercially available from Sigma-Aldrich, USA. All solvents and reagents were of analytical grade and were used without further purification. Precoated silica gel TLC plates were used to monitor reaction progress; a UV lamp (254 nm) was used to visualize the spots. The purity of synthesized compounds was checked by TLC using ethyl acetate and n-hexane $(1: 1)$ as the mobile phase. Melting points were determined on Electrothermal Karl kolb (scientific technical supplier, Germany) and were uncorrected. Infrared (IR) spectra (Supplementary S1) were recorded as $\mathrm{KBr}$ disk using Shimadzu IR apparatus, University of Khartoum, Sudan, and data are given in $\bar{U}\left(\mathrm{~cm}^{-1}\right)$. NMR spectra (Supplementary S2) were determined utilizing either DMSO- $d_{6}$ or $\mathrm{CDCl}_{3}$ as the solvent and recorded on Bruker Avance 111 NMR Spectrophotometer operating at $400 \mathrm{MHz}$ for ${ }^{1} \mathrm{H}$ and at $100 \mathrm{MHz}$ for ${ }^{13} \mathrm{C} \mathrm{NMR}$ at the research center, College of Pharmacy, Cairo University, Egypt.

\subsection{Methods}

3.2.1. Synthesis of Adamantane-1-Carboxylic Acid Methyl Ester (10) and Adamantane-1-carbohydrazide (11). 


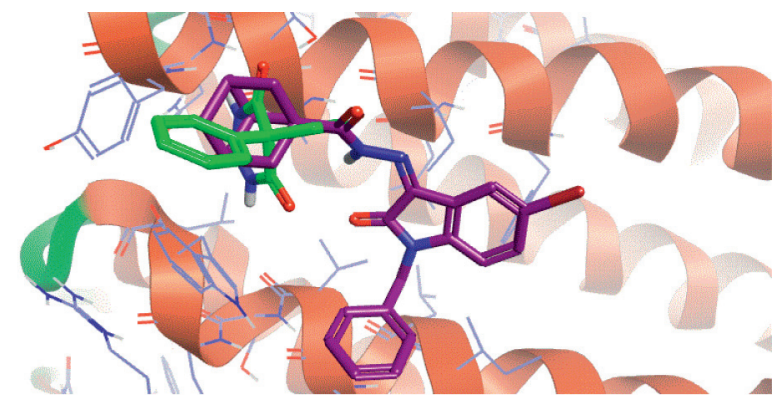

FIGURE 5: $3 \mathrm{D}$ interaction of the $\mathrm{GABA}_{\mathrm{A}}$ receptor with phenobarbital and compound 23; phenobarbitone: green color; compound 23: violet color.

Compounds 10 and 11 were synthesized according to the reported procedure [27, 28].

Adamantane-1-carboxylic acid methyl ester (10): M. P: $45^{\circ} \mathrm{C}$, Lit (46) [27], yield\%: 85, physical appearance: white, characteristic odor crystal, and IR: $\overline{\mathrm{U}} \mathrm{cm}^{-1} 3431(\mathrm{C}=\mathrm{O}$ overtone), 2906 (aliphatic C-H stretching), $1730(\mathrm{C}=\mathrm{O})$, 1238 (C-O stretching).

Adamantane-1-carbohydrazide (11): M. P: $160^{\circ} \mathrm{C}$, yield \%: 98, physical appearance: white, odorless crystal, and IR: $\bar{U}$ $\mathrm{cm}^{-1} 3483$ (NH stretching), 3328 and $3280\left(\mathrm{NH}_{2}\right.$ stretching), 2902 (aliphatic C-H stretching), 1618 (amide $\mathrm{C}=\mathrm{O}$ stretching).

3.2.2. Synthesis of 1-Hydroxymethylisatins (15) and (16). Compounds 15 and 16 were synthesized according to the reported procedure [29].

Synthesis of 1-(hydroxymethyl)indoline-2,3-dione (15): M. P: $100-104^{\circ} \mathrm{C}$, yield\%: 50 , physical appearance: orange, odorless powder, and IR: $\overline{\mathrm{U}} \mathrm{cm}^{-1} 3446$ (broad band $\mathrm{OH}$ stretching), 2979 (ArH stretching), 2921 (aliphatic C-H stretching), 1733 (Ar-C=O), 1612, 1469 (aromatic $\mathrm{C}=\mathrm{C}$ stretching), 1101 (C-O stretching).

Synthesis of 5-bromo-1-(hydroxymethyl)indoline2,3-dione (16): M. P: $105^{\circ} \mathrm{C}$, yield\%: 50, physical appearance: pale orange, odorless powder, and IR: $\overline{\mathrm{U}} \mathrm{cm}^{-1} 3444$ (broad band OH stretching), 2987 (ArH stretching), 2920 (aliphatic C-H stretching), 1737 (Ar-C=O), 1618, 1461 (aromatic $\mathrm{C}=\mathrm{C}$ stretching), 1103 (C-O stretching).

3.2.3. Synthesis of 1-Benzyl-5-bromoindoline-2,3-dione (17). Compound 17 was synthesized according to the previously reported procedure [29].

M. P: $130^{\circ} \mathrm{C}$, yield \%: 62 , physical appearance: red, odorless crystal, and IR: $\overline{\mathrm{U} \mathrm{cm}} \mathrm{cm}^{-1} 3440$ (C= O overtone), 3091 (ArH stretching), 2916 (aliphatic C-H stretching), 1735 (Ar$\mathrm{C}=\mathrm{O}$ ), 1604, 1467, 1438 (aromatic $\mathrm{C}=\mathrm{C}$ stretching).

3.2.4. Synthesis of Target Compounds 18-23. The designed Schiff bases 18-23 were obtained following the reported method [11]. Equimolar quantities (0.003 moles) of appropriate isatin and adamantane-1-carbohydrazide were dissolved in $20 \mathrm{~mL}$ of warm ethanol and refluxed for 12 hours in the presence of 4 drops of glacial acetic acid. The reaction was monitored for completion by TLC, then the solvent was evaporated, and the solid product was obtained and recrystallized from the appropriate solvent.

(Z)- $\mathrm{N}^{\prime}$-(2-oxoindolin-3-ylidene)adamantane-1-carbohy drazide (18): M. P: $>300^{\circ} \mathrm{C}$, yield \%: 73 , physical appearance: yellow, odorless crystal, and IR: $\overline{\mathrm{U}} \mathrm{cm}^{-1} 3182$ (NH stretching), 2908 (aliphatic C-H stretching), 1691 (C=ONHN stretching), 1614, 1525, 1463 (aromatic $\mathrm{C}=\mathrm{C}$ stretching). ${ }^{1} \mathrm{H}$ NMR-DMSO- $d_{6}: \delta$ ppm 1.6-2.05 $(\mathrm{m}, 15 \mathrm{H}$, adamantane moiety hydrogens), 7.61-7.63 (m, 1H, ArH), 7.64-7.74 (m, 1H, ArH ), 7.75-8.14 (m, 1H, ArH), 8.20-8.22 (m, 1H, ArH), 9.02 (brs, 1H, ArNHCO), 9.83 (brs, $1 \mathrm{H},-\mathrm{CONHN}) .{ }^{13} \mathrm{C}$ NMR-DMSO- $d_{6}: \delta$ ppm 39.14, 39.70, 39.97, 40.25, 40.53, 40.81 (adamantane carbons), 59.22 (-CCONH), 123.98, 127.37, 129.01, 133.75, 140.93 (Ar-C), 161.15 (NHCO).

(Z)- $\mathrm{N}^{\prime}$-(5-bromo-2-oxoindolin-3-ylidene) adamantane1-carbohydrazide (19): M. P: $>300^{\circ} \mathrm{C}$, yield\%: 60 , physical appearance: yellow, odorless powder, and IR: $\overline{\mathrm{U}} \mathrm{cm}^{-1} 3269$ (CONH stretching), 3213 (NNH stretching), 3039 (ArH stretching), 2902 (aliphatic C-H stretching), 1706 (CONH) 1681 (CONHN stretching), 1616, 1519, 1460 (aromatic C=C stretching). ${ }^{1} \mathrm{H}$ NMR-DMSO- $d_{6}: \delta$ ppm $1.73-2.05(\mathrm{~m}, 15 \mathrm{H}$, adamantane moiety hydrogens), 6.93 (s, 1H, ArH), 7.56-7.64 (m, 2H, ArH), 11.44 (brs, 1H, ArNHCO), 13.28 (brs, 1H, -CONHN). ${ }^{13} \mathrm{C}$ NMR-DMSO- $d_{6}: \delta$ ppm 39.15, 39.71, 39.98, 40.26, 40.54, 40.81 (adamantane carbons), 47.91 (-CCONH), 110.87, 120.72, 122.62, 128.93, 130.03, 148.51 (Ar-C).

(Z)- $\mathrm{N}^{\prime}$-(5-chloro-2-oxoindolin-3-ylidene) adamantane1-carbohydrazide (20): M. P: $>300^{\circ} \mathrm{C}$, yield $\%: 82^{\circ} \mathrm{C}$, physical appearance: deep yellow, odorless crystal, and IR: $\overline{\mathbf{U}} \mathrm{cm}^{-1}$ 3263 (CONH stretching), 3209 (NNH stretching), 3047 (ArH stretching) 2910 (aliphatic C-H stretching), 1697 (CONHN stretching), 1618, 1515, 1458 (aromatic $\mathrm{C}=\mathrm{C}$ stretching).

(Z)-N'-(1-(hydroxymethyl)-2-oxoindolin-3-ylidene)adamantane-1-carbohydrazide (21): M. P: $220^{\circ} \mathrm{C}$, yield $\%$ : 67 , physical appearance: pale orange, odorless powder, and IR: $\bar{U}$ $\mathrm{cm}^{-1} 3263$ (broad band $\mathrm{OH}$ stretching), 3037 (ArH stretching), 2904 (aliphatic C-H stretching), 1741 (CONH) 1660 (C=ONHN stretching), 1614, 1515, 1452 (aromatic $\mathrm{C}=\mathrm{C}$ stretching), 1344 (C-O stretching). ${ }^{1} \mathrm{H}$ NMR-DMSO- $d_{6}$, $\mathrm{CDCl}_{3}: \delta$ ppm 1.64-1.94 (m, 15H, adamantane moiety hydrogens), 3.94 (s, 2H, ArNCH $\left.{ }_{2}\right), 6.45(\mathrm{~d}, J=12,1 \mathrm{H}, \operatorname{ArH})$, 7.06-7.27 (m, 2H, ArH), 7.50-7.63 (m, 1H, ArH), 8.89 (brs, $1 \mathrm{H}, \mathrm{CH}_{2} \mathrm{OH}$ ), 10.34 (brs, $1 \mathrm{H},-\mathrm{CONHN}$ ). ${ }^{13} \mathrm{C}$ NMR-DMSO$d_{6}, \mathrm{CDCl}_{3}: \delta$ ppm 36.04, 38.33, 38.51, 39.06, 40.10, 40.31 (adamantane carbons), $51.02(-\mathrm{CCONH}), 73.34\left(\mathrm{NCH}_{2} \mathrm{OH}\right)$, 176.30 (ArNCO). MS, Rel. Int (\%): 206 (5\%); 177(5\%); 163 (5\%); 135(100\%); 107 (12\%); 93 (20\%); 91 (5\%); 79 (18\%); 77 (6\%); 67 (6\%); 41 (5\%).

(Z)-N'-(5-bromo-1-(hydroxymethyl)-2-oxoindolin-3-ylidene) adamantane-1-carbohydrazide (22): M. P: $210^{\circ} \mathrm{C}$, yield \%: 47, physical appearance: yellow, odorless powder, and IR: $\bar{U}$ $\mathrm{cm}^{-1} 3255$ (broad band OH stretching), 2904 (aliphatic C-H stretching), 1743 (CONH) 1660 (CONHN stretching), 1615, 1514,1452 (aromatic $\mathrm{C}=\mathrm{C}$ stretching), 1344 (C-O stretching). ${ }^{1} \mathrm{H}$ NMR-DMSO- $d_{6}$ : $\delta$ ppm 1.6-2.1 $(\mathrm{m}, 15 \mathrm{H}$, adamantane moiety hydrogens), 3.58 (s, 2H, $\operatorname{ArNCH} 2), 6.51$ (d, $J=12,1 \mathrm{H}$, ArH), 7.26-7.29 (d, J=12, 1H, ArH), 7.67 (s, 1H, ArH), 8.74 
(brs, $1 \mathrm{H}, \mathrm{CH}_{2} \mathrm{OH}$ ), 10.67 (brs, $1 \mathrm{H},-\mathrm{CONHN}$ ). MS, Rel. Int (\%): 206 (5\%); 177(5\%); 163 (5\%); 135(100\%); 107 (12\%); 93 (20\%); 91 (5\%); 79 (18\%); 77 (6\%); 67 (6\%); 41 (5\%).

(Z)-N'-(1-benzyl-5-bromo-2-oxoindolin-3-ylidene) adamantane-1-carbohydrazide (23): M. P: $300^{\circ} \mathrm{C}$, yield \%: 75, physical appearance: yellow, odorless powder, and IR: $\bar{U}$ $\mathrm{cm}^{-1} 3249$ (NH stretching), 3047 (ArH stretching), 2906 (aliphatic C-H stretching), 1699 (CONHN stretching), 1608, 1514, 1467 (aromatic C $=\mathrm{C}$ stretching). ${ }^{1} \mathrm{H}$ NMR$\mathrm{CDCl}_{3}: \delta \mathrm{ppm} 1.80-2.13(\mathrm{~m}, 15 \mathrm{H}$, adamantane moiety hydrogens), 4.97 (s, 2H, $\left.\operatorname{ArNCH}{ }_{2}\right), 6.65(\mathrm{~d}, J=8,1 \mathrm{H}, \mathrm{ArH})$, 7.28-7.40 (m, 6H, ArH), 7.97 (s, 1H, ArH), 13.34 (brs, 1H, $-\mathrm{CONHN}) .{ }^{13} \mathrm{C}$ NMR-CDCl $3: \delta$ ppm $27.95,36.35,38.90$, 41.28 (adamantane carbons), $43.56\left(\mathrm{ArNCH}_{2}\right), 111.38$, $116.57,121.69,124.76,127.19,128.22,129.10,133.60$, 134.38, $141.16(\operatorname{Ar}-\mathrm{C}), 135.21(\operatorname{ArC}=\mathrm{N}), 161.25(\mathrm{NHCO})$, 175.29 (ArNCO).

\subsubsection{Anticonvulsant Activity}

Experimental Animals. Wistar albino rats of both sexes, weighing about $70-130 \mathrm{~g}$, were housed under standard environmental conditions of temperature (12 hours light/dark cycle; $24 \pm 2^{\circ} \mathrm{C} ; 30-70 \%$ humidity) and had ad libitum access to purified water and food. All animals fasted overnight prior to the experiment with free access to water. Animals were adapted to the laboratory condition for a week before initiating the experiments. Prior to starting the experiment, all experimental animal protocols were approved by the Institutional Animal Ethical Committee (IAEC) of Faculty of Pharmacy, Omdurman Islamic University, constituted in accordance with the guidelines of the Committee for the Purpose of Control and Supervision of Experiments on Animals (CPCSEA).

Chemicals. Standard convulsive agents, PTZ was obtained from Sigma-Aldrich (St. Louis, MO, USA), and phenobarbital was obtained from Shanghai Pharmaceutical Company (Khartoum, Sudan).

Experimental Protocol. This investigation was performed following the Antiepileptic Drug Development Program Protocol (ADDP) [44]. Six synthetic compounds (18-23) were investigated for anticonvulsant activity in albino rats, which were divided into fifteen groups $(N=4)$. All groups were injected subcutaneously in a loose fold of skin on the back of the neck with PTZ $(70 \mathrm{mg} / \mathrm{kg})$ as a chemical epileptic inducer. In the first group, rats were orally administered methylcellulose $5 \%$ as the vehicle control (negative control), and in the second and third groups, rats were orally (p.o) administered phenobarbital 30 and $100 \mathrm{mg} / \mathrm{kg}$, respectively, as reference anticonvulsant drugs for comparison. The remaining groups were orally (p. o) administered synthetic compounds each in different doses (30 and $100 \mathrm{mg} / \mathrm{kg}$ ) one hour before s. c PTZ $70 \mathrm{mg} / \mathrm{kg}$. Animals were placed in isolation cages to minimize stress and then were observed for $30 \mathrm{~min}, 1,4$, and 24 hours for signs of neurological deficits and anticonvulsant activities.
Measuring of Anticonvulsant Activities. Protection rate \% against PTZ-induced seizure was measured by the following equation: protection rate $\%=N_{\mathrm{C}}-N_{\mathrm{T}} / N_{\mathrm{C}} \times 100$, where $N_{C}$ is the number of seizure attacks during 1 hour after seizure induction in the control group and $N_{\mathrm{T}}$ is the number of seizure attacks during 1 hour after seizure induction in the treated group. Furthermore, convulsion latency was measured as the onset time (seconds) of convulsion after seizure induction. Moreover, the duration of convulsion (seconds) was calculated by following the formula, time after completion of convulsion - the onset time of convulsion.

Statistical Analysis. Data were expressed as protection \%, seizure duration, and latency time in seconds \pm SEM and analyzed by two-tailed Student's test to determine the significance of the difference between the control group and rats treated with the test compounds. The difference in results was considered significant when the $P$ value $<0.05$. All statistical calculations were carried out using GraphPad Prism 5 (GraphPad Software Inc., San Diego, CA, USA) [45].

\subsubsection{Computational Studies}

Molecular Docking. The 3D structure of the $\mathrm{GABA}_{\mathrm{A}}$ receptor was downloaded from the protein data bank (PDB ID: 3IP9). The energy of this target was minimized via Cresset Flare software [46]. The chemical structures of compounds were drawn via ChemDraw software, and the $3 \mathrm{D}$ structure was generated in mol2 with Open Babel software [47]. The default settings of Cresset Flare software were used for the docking process [46].

Drug-Likeness Studies. The prediction of ADMET properties, the number of rotatable bonds, topological polar surface area (TPSA), and the number of hydrogen bond donors (HBD) and acceptors (HBA) for all synthesized compounds were estimated using SwissADME (available at http://www. swissadme.ch.com).

\section{Conclusion}

In the present work, six adamantane-isatin conjugates (18-23) were synthesized with the aim of investigating their anticonvulsant activity. Compound 23 was the most efficacious and provided significant protection against PTZinduced seizure with minimal neurotoxicity. Molecular docking studies suggested $\mathrm{GABA}_{\mathrm{A}}$ receptor as a potential target, and in silico ADME screening revealed that the pharmaceutical properties of compound 23 are within the specified limit.

\section{Data Availability}

The data used to support the findings of this study are available from the corresponding author upon request. 


\section{Conflicts of Interest}

The authors declare no conflicts of interest.

\section{Supplementary Materials}

IR (Supplementary 1) and NMR (Supplementary 2) spectral data are provided for the synthesized compounds. (Supplementary Materials)

\section{References}

[1] G. Saravanan, V. Alagarsamy, and P. Dineshkumar, "Anticonvulsant activity of novel 1-(morpholinomethyl)-3-substituted isatin derivatives," Bulletin of Faculty of Pharmacy, Cairo University, vol. 52, no. 1, pp. 115-124, 2014.

[2] World Health Organization, WHO|Epilepsy: A Public Health Imperative, World Health Organization, Geneva, Switzerland, 2019.

[3] W. Löscher and D. Schmidt, "New horizons in the development of antiepileptic drugs: innovative strategies," Epilepsy Research, vol. 69, no. 3, pp. 183-272, 2006.

[4] M. Bialer, "Chemical properties of antiepileptic drugs (AEDs)," Advanced Drug Delivery Reviews, vol. 64, no. 10, pp. 887-895, 2012.

[5] H. S. White, "Preclinical development of antiepileptic drugs: past, present, and future directions," Epilepsia, vol. 44, no. Suppl 7, pp. 2-8, 2003.

[6] V. G. Ugale and S. B. Bari, "Quinazolines: new horizons in anticonvulsant therapy," European Journal of Medicinal Chemistry, vol. 80, pp. 447-501, 2014.

[7] W. Löscher, H. Klitgaard, R. E. Twyman, and D. Schmidt, "New avenues for anti-epileptic drug discovery and development," Nature Reviews Drug Discovery, vol. 12, no. 10, pp. 757-776, 2013.

[8] H. Kaur, B. Kumar, and B. Medhi, "Antiepileptic drugs in development pipeline: a recent update," eNeurologicalSci, vol. 4, pp. 42-51, 2016.

[9] F. A. Khan and A. Maalik, "Advances in pharmacology of isatin and its derivatives: a review," Tropical Journal of Pharmaceutical Research, vol. 14, no. 10, pp. 1937-1942, 2015.

[10] T. Aboul-Fadl, H. A. Abdel-Aziz, M. K. Abdel-Hamid, T. Elsaman, J. Thanassi, and M. J. Pucci, "Schiff bases of indoline-2,3-dione: potential novel inhibitors of mycobacterium tuberculosis (Mtb) DNA gyrase," Molecules, vol. 16, no. 9, 2011.

[11] M. M. Ibrahim, T. Elsaman, and M. Y. Al-Nour, "Synthesis, anti-inflammatory activity, and in silico study of novel diclofenac and isatin conjugates," International Journal of Medicinal Chemistry, vol. 2018, pp. 1-11, Article ID 9139786, 2018.

[12] S. Ibrahim and T. Elsaman, "Cytotoxic and anticancer activities of indoline-2,3-dione (isatin) and its derivatives," Journal of Pharmaceutical Research International, vol. 21, no. 2, pp. 1-19, 2018.

[13] P. Phogat and P. Singh, "A mini review on central nervous system potential of isatin derivatives," Central Nervous System Agents in Medicinal Chemistry, vol. 15, no. 1, pp. 28-31, 2015.

[14] V. Eggadi, U. Kulandaivelu, S. B. Sharvanabhava, and V. R. Jupally, "Screening of the anticonvulsant activity of some isatin derivatives in experimental seizure models and its effect on brain GABA levels in mice," American Journal of Pharmacological Sciences, vol. 1, no. 3, pp. 42-46, 2013.
[15] L. Wanka, K. Iqbal, and P. R. Schreiner, "The lipophilic bullet hits the targets: medicinal chemistry of adamantane derivatives," Chemical Reviews, vol. 113, no. 5, pp. 3516-3604, 2013.

[16] K. Gerzon, E. V. Krumkalns, R. L. Brindle, F. J. Marshall, and M. A. Root, "The adamantyl group in medicinal agents. I. Hypoglycemic N-arylsulfonyl-N'-adamantylureas," Journal of Medicinal Chemistry, vol. 6, no. 6, pp. 760-763, 1963.

[17] R. T. Rapala, R. J. Kraay, and K. Gerzon, "The adamantyl group in medicinal agents. II. Anabolic steroid 17 $\beta$-adamantoates," Journal of Medicinal Chemistry, vol. 8, no. 5, pp. 580-583, 1965.

[18] K. Gerzon, D. J. Tobias, R. E. Holmes, R. E. Rathbun, and R. W. Kattau, "The adamantyl group in medicinal agents. IV. Sedative action of 3,5,7-Trimethyladamantane-1-carboxamideland related agents," Journal of Medicinal Chemistry, vol. 10, no. 4, pp. 603-606, 1967.

[19] J. Vamecq, K. Van Derpoorten, J. H. Poupaert, J. Balzarini, E. De Clercq, and J. P. Stables, "Anticonvulsant phenytoinergic pharmacophores and anti-HIV activity - preliminary evidence for the dual requirement of the 4-aminophthalimide platform and the N-(1-adamantyl) substitution for antiviral properties," Life Sciences, vol. 63, no. 19, pp. PL267-PL274, 1998.

[20] M. A. Ilies, B. Masereel, S. Rolin et al., "Carbonic anhydrase inhibitors: aromatic and heterocyclic sulfonamides incorporating adamantyl moieties with strong anticonvulsant activity," Bioorganic \& Medicinal Chemistry, vol. 12, no. 10, pp. 2717-2726, 2004.

[21] G. Lamoureux and G. Artavia, "Use of the adamantane structure in medicinal chemistry," Current Medicinal Chemistry, vol. 17, no. 26, pp. 2967-2978, 2010.

[22] G. Zoidis, I. Papanastasiou, I. Dotsikas et al., "The novel GABA adamantane derivative (AdGABA): design, synthesis, and activity relationship with gabapentin," Bioorganic \& Medicinal Chemistry, vol. 13, no. 8, pp. 2791-2798, 2005.

[23] S. M. Antonov, J. W. Johnson, N. Y. Lukomskaya, N. N. Potapyeva, V. E. Gmiro, and L. G. Magazanik, "Novel adamantane derivatives act as blockers of open ligand-gated channels and as anticonvulsants," Molecular Pharmacology, vol. 47, no. 3, pp. 558-567, 1995.

[24] N. Choudhary and V. Singh, "Insights about multi-targeting and synergistic neuromodulators in Ayurvedic herbs against epilepsy: integrated computational studies on drug-target and protein-protein interaction networks," Scientific Reports, vol. 9, no. 1, pp. 1-23, 2019.

[25] C. Viegas-Junior, A. Danuello, V. Da Silva Bolzani, E. J. Barreiro, and C. A. M. Fraga, "Molecular hybridization: a useful tool in the design of new drug prototypes," Current Medicinal Chemistry, vol. 14, no. 17, pp. 1829-1852, 2007.

[26] V. Ivasiv, C. Albertini, A. E. Gonçalves, M. Rossi, and M. L. Bolognesi, "Molecular hybridization as a tool for designing multitarget drug candidates for complex diseases," Current Topics in Medicinal Chemistry, vol. 19, no. 19, pp. 1694-1711, 2019.

[27] A. A. El-Emam, K. A. Alrashood, M. A. Al-Omar, and A. M. S. Al-Tamimi, "Synthesis and antimicrobial activity of N'-heteroarylidene-1- adamantylcarbohydrazides and (士)-2-(1-adamantyl)-4-acetyl 5-[5-(4- substituted phenyl3-isoxazolyl)]-1,3,4-oxadiazolines," Molecules, vol. 17, no. 3, pp. 3475-3483, 2012.

[28] R. Ficarra, P. Ficarra, A. Tommasini, G. Fenech, F. C. Pizzimenti, and G. Bisignano, "[Hydrazides of 1-adamantane carboxylic acid with presumed antimicrobial action]," Bollettino Chimico Farmaceutico, vol. 123, no. 7, pp. 317-321, 1984. 
[29] T. Aboul-Fadl, F. A. S. Bin-Jubair, and O. Aboul-Wafa, "Schiff bases of indoline-2, 3-dione (isatin) derivatives and nalidixic acid carbohydrazide, synthesis, antitubercular activity and pharmacophoric model building," European Journal of Medicinal Chemistry, vol. 45, no. 10, pp. 4578-4586, 2010.

[30] G. S. Hassan, A. A. El-Emam, L. M. Gad, and A. E. M. Barghash, "Synthesis, antimicrobial and antiviral testing of some new 1-adamantyl analogues," Saudi Pharmaceutical Journal, vol. 18, no. 3, pp. 123-128, 2010.

[31] M. Shmidt, A. Reverdito, L. Kremenchuzky, I. Perillo, and M. Blanco, "Simple and efficient microwave assisted N-alkylation of isatin," Molecules, vol. 13, no. 4, pp. 831-840, 2008.

[32] L. A. McAllister, R. A. McCormick, K. M. James, S. Brand, N. Willetts, and D. J. Procter, "A fluorous, pummerer cyclative-capture strategy for the synthesis of N-heterocycles," Chemistry - A European Journal, vol. 13, no. 4, pp. 1032-1046, 2007.

[33] Ö. Güzel, N. Karalı, and A. Salman, "Synthesis and antituberculosis activity of 5-methyl/trifluoromethoxy-1H-indole-2, 3dione 3-thiosemicarbazone derivatives," Bioorganic \& Medicinal Chemistry, vol. 16, no. 19, pp. 8976-8987, 2008.

[34] A. A. Kadi, N. R. El-Brollosy, O. A. Al-Deeb, E. E. Habib, T. M. Ibrahim, and A. A. El-Emam, "Synthesis, antimicrobial, and anti-inflammatory activities of novel 2-(1adamantyl)-5-substituted-1,3,4-oxadiazoles and 2-(1-adamantylamino)-5-substituted-1,3,4-thiadiazoles," European Journal of Medicinal Chemistry, vol. 42, no. 2, pp. 235-242, 2007.

[35] M. M. E. Mudawi, M. F. Abd El-wahab, A. Y. A. Yassin, R. S. Habeballa, and M. M. Alshehri, "Evaluation of anticonvulsant activity and HPLC-DAD profiling of Achillea fragrantissima (Gaisoom) extracts growing in Saudi Arabia," Asian Journal of Pharmaceutical Research and Health Care, vol. 9, no. 3, p. 92, 2017.

[36] A. M. Waszkielewicz, A. Gunia-Krzyżak, M. Cegła, and H. Marona, "Synthesis and evaluation of anticonvulsant activity of N-(2, 5-dimethylphenoxy)- and N-[(2, 3, 5-trimethylphenoxy) alkyl]aminoalkanols," Acta Poloniae Pharmaceutica, vol. 72, no. 1, pp. 89-99, 2015.

[37] E. Bruno, M. R. Buemi, L. De Luca et al., "In Vivo evaluation of selective carbonic anhydrase inhibitors as potential anticonvulsant agents," ChemMedChem, vol. 11, no. 16, pp. 1812-1818, 2016.

[38] M. F. Zayed and M. H. Hassan, "Synthesis and biological evaluation studies of novel quinazolinone derivatives as antibacterial and anti-inflammatory agents," Saudi Pharmaceutical Journal, vol. 22, no. 2, pp. 157-162, 2014.

[39] R. Citraro, M. Navarra, A. Leo et al., "The anticonvulsant activity of a flavonoid-rich extract from orange juice involves both NMDA and GABA-benzodiazepine receptor complexes," Molecules, vol. 21, no. 9, p. 1261, 2016.

[40] W. Lasoñ, M. Chlebicka, and K. Rejdak, "Research advances in basic mechanisms of seizures and antiepileptic drug action," Pharmacological Reports, vol. 65, no. 4, pp. 787-801, 2013.

[41] W. M. El Kayal, S. Y. Shtrygol, S. V. Zalevskyi et al., "Synthesis, in vivo and in silico anticonvulsant activity studies of new derivatives of 2-(2, 4-dioxo-1, 4-dihydroquinazolin-3(2H)-yl) acetamide," European Journal of Medicinal Chemistry, vol. 180, pp. 134-142, 2019.

[42] P. Czapinski, B. Blaszczyk, and S. J. Czuczwar, "Mechanisms of action of antiepileptic drugs," Current Topics in Medicinal Chemistry, vol. 5, no. 1, pp. 3-14, 2005.
[43] R. Kumar, T. Singh, H. Singh, S. Jain, and R. K. Roy, "Design, synthesis and anticonvulsant activity of some new 6, 8-halosubstituted-2h-[1, 2, 4] triazino[5,6-b]indole-3(5h)-one/-thione and 6, 8-halo-substituted 5-methyl-2h-[1, 2, 4] triazino[5, 6-b] indol-3(5h)-one/-thione," EXCLI Journal - Experimental and Clinical Sciences, vol. 13, pp. 225-240, 2014.

[44] R. J. Porter, J. J. Cereghino, G. D. Gladding et al., “Antiepileptic drug development program," Cleveland Clinic Quarterly Journal, vol. 51, no. 2, pp. 293-305, 1984.

[45] Z. Chen, R. Bertin, and G. Froldi, "EC 50 estimation of antioxidant activity in DPPH $\AA$ assay using several statistical programs," Food Chemistry, vol. 138, no. 1, pp. 414-420, 2013.

[46] T. Cheeseright, M. Mackey, S. Rose, and A. Vinter, "Molecular field extrema as descriptors of biological activity: definition and validation," Journal of Chemical Information and Modeling, vol. 46, no. 2, pp. 665-676, 2006.

[47] N. M. O’Boyle, M. Banck, C. A. James, C. Morley, T. Vandermeersch, and G. R. Hutchison, "Open Babel: an open chemical toolbox," Journal of Cheminformatics, vol. 3, p. $33,2011$. 